\title{
Teaching diagnostic reasoning: Transitioning from a live to a distance accessible online classroom in an Adult Acute Care Nurse Practitioner Program
}

\author{
Susan J. Appel ${ }^{1}$, Theresa M. Wadas ${ }^{1}$, Michele H. Talley ${ }^{2}$, Anne M. Williams ${ }^{2}$ \\ 1. Capstone College of Nursing, The University of Alabama, Tuscaloosa, Alabama, USA. 2. School of Nursing, University of \\ Alabama Birmingham, Birmingham, Alabama, USA
}

Correspondence: Susan J. Appel. Address: Capstone College of Nursing, The University of Alabama, Box 870358, Tuscaloosa, Alabama, USA. Email: sappel@ua.edu.

Received: February 20, 2013

Accepted: May 7, 2013

Online Published: July 23, 2013

DOI : $10.5430 /$ jnep.v3n12p125

URL: http://dx.doi.org/10.5430/jnep.v3n12p125

\begin{abstract}
The advent of online technologies has led to increased opportunities for colleges of nursing to extend their graduate educational curriculums for expanding numbers of students. Likewise, graduate nursing students now have endless choices regarding programs of study, for which they are no longer limited by geographical locations. Nurse educators are now being confronted with the need to impart increasingly sophisticated knowledge to growing numbers of students via online technologies. Teaching advanced practice students, especially nurse practitioners, within an online teaching platform leads to a special list of challenges for nurse educators. One major issue is the fostering of diagnostic reasoning in an online environment. This article offers an overview of how one Adult Acute Care Nurse Practitioner (ACNP) program transitioned over time from a live classroom curriculum to a distance accessible program.
\end{abstract}

\section{Key words}

Critical thinking, Teaching presence, Distance education, Educational strategies, Simulation

\section{I ntroduction}

Diagnostic reasoning is the complex cognitive process used by clinicians from many health care disciplines to ascertain a correct diagnosis and therefore prescribe appropriate treatment for patients. Knowledge, experience, and the context in which the clinician finds himself or herself underlie data acquisition, the first step in diagnostic reasoning ${ }^{[1]}$. Diagnostic reasoning involves two processes: one is more intuitive, more a gestalt coupled with "skilled know-how" that can guide further history-taking. The other process is more logical and analytical and is reflected by a learner's ability to synthesize the data and generate hypotheses ${ }^{[1-3]}$. Croskerry ${ }^{[2]}$ noted that the intuitive process, labeled System 1, is "fast, frugal, requires little effort, and frequently gets the right answer," while System 2, the analytical process, is engaged primarily when "pathognomicity is low, and uncertainty is correspondingly high." This difference in approach is also noted by Tanner ${ }^{[4]}$ who used as the example the young nurse who, being uncertain, first did a complete physical assessment, then sat with a textbook to analyze the problem. Kosowski and Roberts ${ }^{[5]}$ investigated intuitive decision making among novice nurse practitioners and found that intuition frequently triggered a more analytical approach in their sample. 
Croskerry ${ }^{[2]}$ noted that among physicians, diagnostic accuracy is not as good as would be hoped, with a $20 \%$ to $40 \%$ error rate as estimated by comparing autopsy findings with antemortem diagnoses. Similar statistics are not available for nurse practitioners (NPs). However, Van der Linden, Reijnen and de Vos ${ }^{[6]}$ found in their survey of "junior doctors" and NPs in an emergency department setting, that errors in diagnosis or mismanagement occurred among $1.2 \%$ of patients seen by the junior doctors and $2.7 \%$ of those seen by NPs $(\mathrm{p}=\mathrm{ns})$. This is considerably better than the rates reported by Croskerry ${ }^{[2]}$. The difference possibly reflects a difference in population. However, arriving at the correct diagnosis is critical to good patient outcomes. Therefore clinician-faculty continues to strive to devise effective strategies to teach diagnostic reasoning skills. This becomes especially challenging when moving from a live, synchronous, face-to-face teaching environment to an online, distance accessible format.

This article reviews gradual attempts to transition from a live classroom environment to an online distance accessible program while delivering quality exercises for teaching diagnostic reasoning. The term “distance accessible” is used because program requirements, although online, allow us to bring students to campus for short intensive sessions and to hold periodic synchronized live online classes focused on sharpening diagnostic reasoning skills. Various strategies of teaching critical diagnostic reasoning are presented, using prototypes and similarity recognition to enable students to elucidate case studies.

\section{Conceptual framework}

Our application of a conceptual framework was heavily influenced by the work of Tanner ${ }^{[4]}$ Bowen ${ }^{[1]}$, and Croskerry ${ }^{[2]}$ Tanner's ${ }^{[4]}$ model was developed from the literature to illustrate the collective research finding on how nurses think and develop clinical judgment. Whereas, Bowen ${ }^{[1]}$ and Croskerry ${ }^{[2]}$ focused on the process of diagnostic reasoning within medicine. Within all three models, emphasis was placed on the context from which students come and in which they found themselves as well as what they brought with them to the clinical setting, including knowledge and experience.

Tanner's ${ }^{[4]}$ model included context, process variables, and a feedback loop. Tanner's ${ }^{[4]}$ initial process variable was "noticing", which reflected a student's initial understanding and expectations of the clinical situation, including knowledge of the patient, of the population of patients of this type, and of the standard of care for this sort of patient. We found that a mixture of techniques fostered the student's ability to notice recurring patterns. Techniques to promote noticing patterns of disease manifestations were case studies presented within our synchronized online class sessions and the Objective Structured Clinical Examination (OSCE) lab.

Tanner's ${ }^{[4]}$ second process variable was “interpreting.” During this process both analytic and intuitive reasoning patterns that underlie diagnosis formulation occurred. Faculty and guest lectures produced narrated PowerPoint presentations highlighting the standard guidelines of care, which seemed to cultivate the students' ability to interpret clinical clues leading to diagnosis.

"Responding” followed next, with consideration of various therapeutic strategies and existing evidence, a written record of the encounter (a SOAP note), and implementation of a therapeutic plan. Tanner provided a feedback loop during which the patient's response to treatment was monitored ${ }^{[4]}$. Student/clinician reflection occurred during the process, after which adjustments in the plan of care could be made.

Finally, the student/clinician reflected on the entire process to learn from it. Responding and reflection were both heavily impacted by the course's emphasis on evidence based practice and standard guidelines. The evaluation of what students and faculty believed was helpful came from numerous sources: formal course evaluations, objective testing, evaluation of SOAP notes and input from the standardized patients that students used to conduct complete histories and physicals. Also, input was routinely obtained from clinical preceptors who shared that students were prepared and had essential basic knowledge for the clinical populations. 


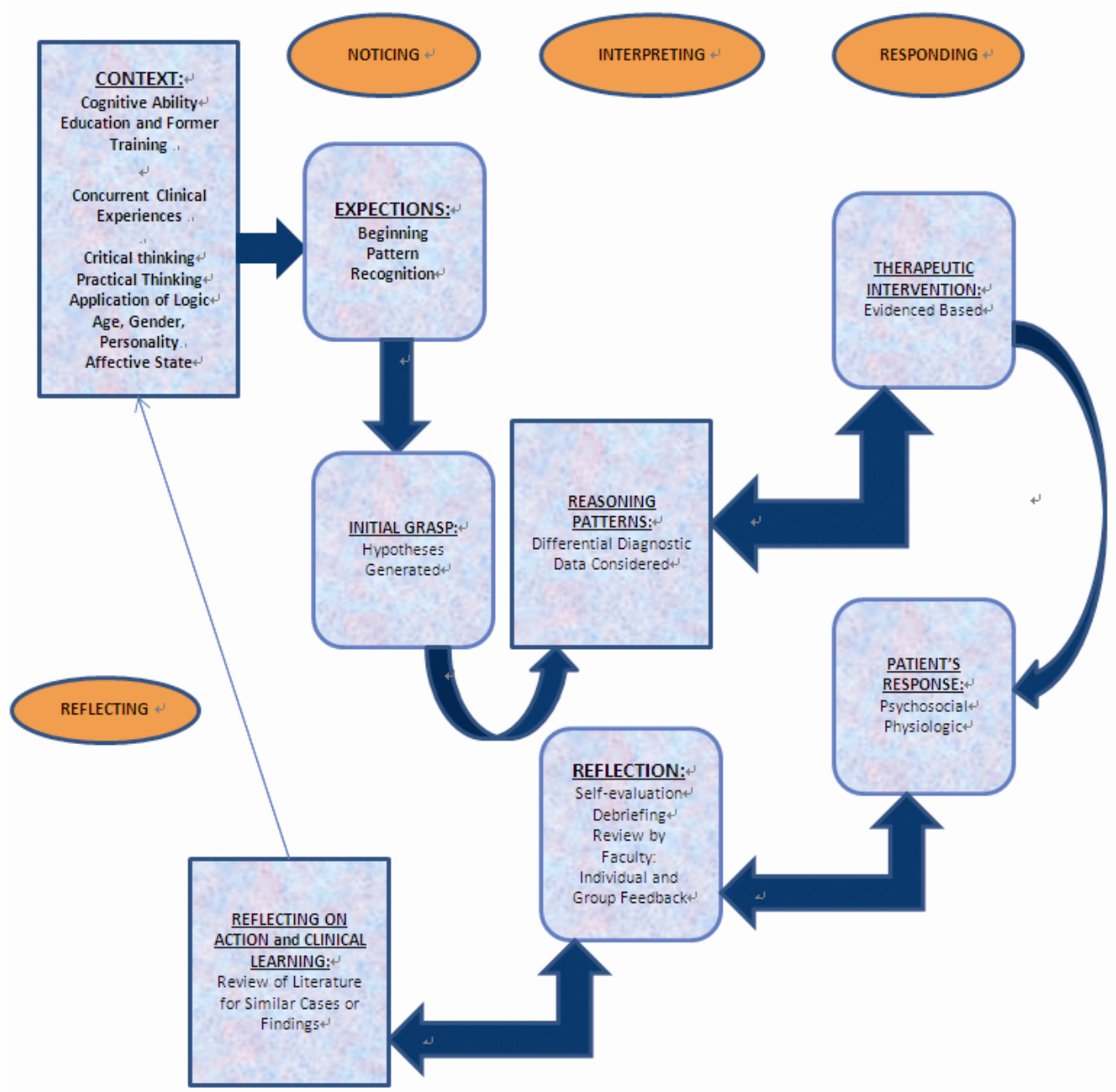

Figure 1. Teaching Diagnostic Reasoning to ACNP Students ${ }^{[2,4]}$

\section{Methods}

For the formidable task of moving an Adult Acute Care Nurse Practitioner curriculum from a live classroom setting to a distance accessible format, we employed various strategies to bridge this transition over time. Two years before the transition we began offering online asynchronous content in module form for on-campus students. Eventually we arranged to offer classes every two weeks, but for longer periods. This two-year period of testing the asynchronous content was especially advantageous to our growth and development as faculty teaching online in a distance accessible program. We soon realized certain content was more amenable to an online asynchronous delivery than a live synchronized interaction as was now available in the newer online "live classroom" feature of our online platform.

Our changes to the ACNP curriculum followed Tanner's ${ }^{[4]}$ model. Many of our ACNP students were increasingly younger and more inexperienced than previous cohorts. Although we recommended that students have at least two years of acute care or critical care experience before being admitted, the standard admission policy for the School of Nursing was only 1 year of clinical experience before beginning the clinical content for the advanced practice NP program. We therefore found ourselves admitting very inexperienced students. Students' limited clinical experience coupled with an online teaching environment led us to devise new plans to adequately teach diagnostic reasoning. We used both an asynchronous learning environment with content modules, and a synchronous format using live, online discussions and live simulated patient experiences. 


\subsection{Noticing}

Because clinical judgment is influenced by the context by which the student came to us, we were concerned that students with limited clinical experiences could not be expected to easily note or notice clinical findings. So we strove to offer case studies in which there were either hallmarks of the case or the red flags of disaster for adverse outcomes. Therefore, once students worked through the online modules, we required both their attendance and participation in synchronized online live classrooms where case studies and corresponding plans of care were discussed ${ }^{[7]}$. The majority of students were able to attend the required live online classroom sessions (as we announced the dates the semester prior), but we did archive these sessions for students who were unable to attend. We also encouraged students to review the cases and the corresponding plan of care from the synchronized class prior to the OSCE, as we intentionally addressed correlating concepts which built on knowledge and skills needed for correct diagnosis. Scaffolding content in a progressive manner and holding students responsible for previous knowledge was key to successful student outcomes. We commonly highlighted conditions presented later within the OSCE lab.

The repetitiveness of this content taught the students beginning pattern recognition. The synchronized live online cases also gave students opportunities to be interactive in answering the cases and for red flags to be highlighted. We chose to use Pattern Recognition (Bowen's "illness scripts") ${ }^{[8]}$ as a major strategy to teach diagnostic reasoning, as this technique is most commonly and successfully used by expert clinicians ${ }^{[1,8]}$. Croskerry ${ }^{[2]}$ noted that repeated exposure to clinical material with the analysis that leads to correct interpretation of the presentation leads to recognition of a pattern. We found sharing repetitive content while extending the concepts that lead to the final formation of an evidence based plan of care to be a key strategy.

\section{Development of asynchronous modules}

The development of the asynchronous learning modules from the traditional classroom presentations served as the backbone of the new online content. These were, due to necessity upgraded. Narrated PowerPoint presentations could be added, as well as links to a variety of content. Videos of live lectures were posted for review at the student's convenience. Although the lecture content was good, the students did not have the opportunity to ask questions of the expert with that configuration. Therefore, once we developed the majority of the content in an asynchronous format, we held "live classrooms” to reintegrate content that was essential to foster students' diagnostic reasoning skills using a case study format leading to formation of an evidenced based plan of care.

\section{Online synchronized live classroom}

We found that presenting case studies with questions and answers followed by class discussion focused on formulating an evidence based plan of care was very helpful when mentoring students to apply basic information learned from the asynchronous content. Patients' problems were presented in abstract forms or as short narratives to allow the student to begin the process of pattern recognition and to formulate a plausible list of differential diagnoses. The class was polled jointly for appropriate interventions based on standards of care for the specific patient population. An overall plan was then formulated by the end of the session.

In our online platform the live classroom option allowed a variety of teaching strategies, including audio, video, application sharing and displaying content from the web or the instructor's or the student's desktop. We found we could lecture in a fashion similar to an actual live classroom, talking with PowerPoint slides or sharing an application on our desktop. The desktop could also be turned over to a specific student to give a presentation or even a guest lecture housed at another university. The live classroom feature also allowed us to archive these activities so students could review them later.

Attendance was taken online during the live classroom sessions. Students were required to actively participate in solving the clinical cases. Points for attendance in the live classroom were part of the grade for the course. The live classroom 
content laid the groundwork for our students to be more successful when we held our on-campus OSCE at mid-term and during final exam periods.

Objective Structured Clinical Examination. OSCEs are often employed as a strategy in nursing, medical and allied health schools to more fully examine or to test clinical skill performance and competencies of students (i.e., communication, clinical examination, procedures/prescription, exercise prescription, and interpretation of results for patients with a variety of physical conditions) ${ }^{[9,10]}$. OSCE exercises provide students with an opportunity to practice targeted assessment skills in a protected simulated setting that does not need one-on-one faculty presence. OSCEs also provided an opportunity to witness student assessment skills in real time, as they are recorded for later review and evaluated.

Our OSCE patients, actors who were given standardized scripts, were chosen to coincide with didactic material presented during the live classrooms. Therefore, the concordance between the live classroom content and the standardized patients was strong, enabling students to be well prepared for the OSCEs. Once the patient actors were prompted by appropriate student questions, they would then provide specific diagnostic findings (i.e., laboratory values, $\mathrm{x}$-rays and electrocardiograms) to the students. The patient actors completed a checklist to assist in evaluating the students' clinical assessment skills as well as their interpersonal skills. The students were then required to write a focused SOAP note with a comprehensive plan of care and complete a self-evaluation. The faculty then viewed the taped patient encounter, actor's checklist, student's self-evaluation and SOAP note to formulate a grade. As part of the debriefing exercise students were given both individual feedback as well as an overview of strengths and areas of growth for the class as a whole. As faculty, we felt strongly that the combinations of the live classroom with the OSCE experiences served to inform us about areas of the curriculum that needed to be reinforced. We also encouraged a reflective practice by having the students contemplate their performance during the OSCE and complete a self-evaluation form. When students identified their own deficits on their self-assessment we did not penalize them for leaving a section out of their history and physical.

\subsection{I nterpreting}

Interpreting involves formulating probable diagnoses and differential diagnoses, as well as assessment skills. After the completion of didactic content for a unit, the students were examined in the OSCE laboratory. Prepared from the case study session, the students were asked to interpret the cases. Students were then asked if the actor was presenting a fully developed case that had clear recognizable patterns or an atypical case that would require a bit more diagnostic data to rule out various differential diagnoses. In the written self-assessment of their OSCE performance and SOAP note, students were encouraged to include their list of differential diagnoses and an ultimate final diagnosis. They were given the opportunity to say if other diagnostic data would have been useful and to clearly elaborate their diagnostic reasoning used during the process.

Problem Based Learning - Problem Based Learning (PBL) is an instructional strategy which is student-centered. PBL is delivered within an open-ended format, presenting ill-defined and ill-structured problems. PBL differs from a case study approach in that in PBL activities the students may not have had access to previous content, but are encouraged to seek out essential content to solve the problem. The case study approach, in contrast, is built on the concept that students have the knowledge basis to solve the case. In PBL, students work in small collaborative groups; the faculty member serves only as a facilitator. Students are encouraged to take accountability for their group and organize as well as direct the learning process with the facilitator's support ${ }^{[11]}$. Promoters of PBL argue that it enhances content knowledge and cultivates the development of communication, problem-solving, and self-directed learning skills ${ }^{[12,13]}$.

Problem Based Learning seemed to have limitations in an online format. Our students expressed one major issue when we used different problem-based cases to teach more content to the class in a PBL format: they felt they learned a great deal concerning the content of the case they presented and much less from the cases presented by their peers. Therefore, when used as a teaching strategy, providing all student groups with the same case may assure the best mastery of the content. This, of course, limits the content that may be covered in a PBL session. 
Having gone from a live classroom to a distance accessible program, another concern arose because our enrollment doubled. With two faculty assigned to each course, those faculty serving in the facilitator role were spread very thin. In theory, we felt PBL was an excellent student-learning activity to teach diagnostic reasoning, but we were confronted by the above limitations that led us to choose a traditional case study approach over a PBL format.

\subsection{Responding}

Further use of the OSCE. Within their SOAP notes, the students were asked to present a fully developed plan of care, based on current evidence based guidelines. In addition, at the end of each OSCE they were instructed to inform the patient actor of their diagnosis and the details of the plan of care. The students were then debriefed by the actors. Later the faculty viewed the OSCE tape, student self-evaluation, and patient evaluation and then correlated them with the student's SOAP notes. Feedback was given by the faculty to each individual student and to the class in general. These activities augmented the clinical experiences of the students where they had opportunities to evaluate actual patients and the patients' families' responses to therapeutic interventions. The feedback from the OCSE was done prior to mid-term and final examinations, acting as a review of course content.

Exercises to Foster Evidence-based Practice. Another activity that dovetails with diagnostic reasoning is finding the best research evidence to guide practice. The phrase "evidence-based (EB) practice" may be viewed as patient care that is empirically-supported based on research or consensus opinion ${ }^{[14]}$.

To teach application of EB practice to our students, specific projects extended over three semesters. The first was for the student to formulate a formal paper which was to be based on a controversial clinical question that had been debated within the research literature. Students formulated a paper that was graded during the first semester of their acute care nurse practitioner didactic specialty courses. During the second nurse practitioner didactic specialty course, the students formulated a PowerPoint presentation. The presentation was based on the finding reported within the EB paper, and then was presented to the class. Discussion and feedback concerning the various presentations were encouraged between the students. During the third semester, containing a nurse practitioner didactic specialty course, students were asked to formulate a poster of their EB practice issue and present it within a public forum. We offered a formal poster presentation at the school and invited faculty and students from other classes and disciplines. Formal judging was done by faculty with acute care backgrounds who did not teach in the acute care program, and awards were given for the best EB practice posters.

\subsection{Reflecting}

Students were strongly encouraged to reflect on their experiences while they were writing their OSCE self-evaluations, being debriefed by the patient actor and receiving feedback from the faculty. Likewise, students were urged to return to the literature and review the case from the OSCE. They were asked to determine if the case had hallmark findings or red flags or was not fully developed. This intervention is of supreme importance, as many diagnostic decisions are determined based on pattern recognition ${ }^{[2]}$. When the disease is not fully manifested, then the student may not be able to recognize the pattern and misdiagnose it as another pathological entity ${ }^{[2]}$. Emphasis should also be focused on common atypical presentations so that red flags are not missed.

\section{Evaluations by preceptors, students and the medical community}

We had been fortunate to have a set cohort of physicians and acute care nurse practitioners who were familiar with our program and repeatedly served as clinical preceptors. Over time we began to receive increasingly positive input from our clinical preceptors. It was felt that the students although less experienced as Registered Nurses were manifesting higher levels of differential diagnostic skills. As faculty we also felt that the OSCEs were preparing the students' for the clinical interactions with patients, families and preceptors. 
At the beginning of the acute care program students reported on their course evaluations that they commonly found the OSCEs to be very intimidating and stressful, while near the completion of the program students reported that they began to regard the OSCE experiences as invaluable. Students also indicated that they came to view the individual input from faculty as helpful and not condemning. Overall, our graduates were sought after by the medical community. One medical intensive care (ICU) director from the major medical center contacted us and asked for recommendations of ten students' and hired six of our new graduates to staff the medical ICU 0700-2300. The cut back in the resident physicians' hours has offered many opportunities for our graduates.

\section{Conclusion}

As faculty we found the Live Classrooms, OSCEs and EB practice activities to all be successful strategies to enhance the teaching of diagnostic reasoning skills. These activities encouraged the students to focus on pattern recognition, reflective practice, and finding the best evidence to support practice decisions. Overall, our students' program completion, graduation rates and certification pass rates remained high. The choice of ideal strategies to foster diagnostic reasoning skills within a distance accessible online program may be dependent on programmatic resources and philosophy of the faculty. We felt fortunate to have administrative support to provide OSCE experiences for our students with paid actors. Likewise, a high level of commitment by the faculty to provide individualized feedback is also imperative after an OSCE to encourage pattern recognition and reflective practice. An additional positive outcome was that the faculty interactions with the students and students' interactions with each other helped develop a community of scholarship online. Students also remarked that there was a strong faculty presence within these courses.

The interventions discussed provided the tools for faculty to use in the classroom or online to help NP students determine which data to collect and which are important in developing plausible differential diagnoses. Exposure of students to both individual and group feedback by expert faculty NPs may be the essential activity to begin to encourage reflective practice of novice student nurse practitioners as they transition though various stages of proficiency and archive the expert role.

In short, in order to foster diagnostic reasoning skills, the faculty must in some fashion (i.e., live or virtually) escort students to the examination room to perform an independent assessment of the patient, while assessing the students' clinical reasoning ability ${ }^{[15]}$. When providing structured feedback to students, faculty serve as models while providing cognitive feedback which highlights diagnostically useful data, irrelevant findings and discriminating findings leading to correct diagnosis. Teaching student NPs to think critically versus not simply memorizing and reciting facts is the essential goal of fostering diagnostic reasoning.

\section{Acknowledgement}

The authors would like to thank: Dr. N. Elizabeth Stullenbarger, Distinguished Service Professor Emeritus and at the time of this work Senior Associate Dean for Academic Affairs, University of Alabama Schoolof Nusing, Birmingham for her support of the Adult Acute Care Nurse Practitioner program.

\section{References}

[1] Bowen, JL. Educational strategies to promote clinical diagnostic reasoning. New England Journal of Medicine. 2006; 355(21): 2217-2225. PMid:17124019 http://dx.doi.org/10.1056/NEJMra054782

[2] Croskerry, P. A universal model of diagnostic reasoning. Academic Medicine: Journal of the Association of American Medical Colleges. 2009; 84(8): 1022-1028. PMid:19638766 http://dx. Doi.org/10.1097/ACM.0b013e3181ace703

[3] Ritter, BJ. An analysis of expert nurse practitioners' diagnostic reasoning. Journal of the American Academy of Nurse Practitioners. 2003; 15(3): 137-141. http://dx.doi.org/10.1111/j.1745-7599.2003.tb00270.x

[4] Tanner, C A. Thinking like a nurse: A research-based model of clinical judgment in nursing. The Journal of Nursing Education. 2006; 45(6): 204-211. PMid:16780008 
[5] Kosowski, MM, Roberts, V W. When protocols are not enough: Intuitive decision making by novice nurse practitioners. Journal of Holistic Nursing: Official Journal of the American Holistic Nurses' Association. 2003; 21(1): 52-72. PMid:12666615 http://dx.doi.org/10.1177/0898010102250275

[6] Van der Linden, C, Reijnen, R, de Vos, R. Diagnostic accuracy of nurse practitioners versus physicians related to minor illnesses and injuries. Journal of Emergency Nursing. 2010; 36(4): 311-316. PMid:20624563 http://dx.doi.org/10.1016/j.jen.2009.08.012

[7] Overstreet, M. Ee-chats: The seven components of nursing debriefing. Journal of Continuing Education in Nursing. 2010; 41(12): 538-539. PMid:21117547 http://dx.doi.org/10.3928/00220124-20101122-05

[8] Barrows, HS, Feltovich, PJ. The clinical reasoning process. Medical Education. 1987; 21(2): 86-91. PMid:3574170 http://dx.doi.org/10.1111/j.1365-2923.1987.tb00671.x

[9] DeMuth, R., Phillips, J, Wagner, D. An OSCE remediation experience focused on diagnostic reasoning. Medical Teacher. 2011; 33(7): 592-593. PMid:21837815

[10] White, CB, Ross, P, Gruppen, LD. Remediating student's failed OSCE performances at one school: The effects of self-assessment, reflection, and feedback. Academic Medicine. 2009; 84(5): 651-654. PMid:19704203 http://dx.doi.org/10.1097/ACM.0b013e31819fb9de

[11] Azer, SA. Introducing a problem-based learning program: 12 tips for success. Medical Teacher. 2011; 33(10): 808-813. PMid:21942480 http://dx.doi.org/10.3109/0142159X.2011.558137

[12] Ployzois, I, Claffey, N, Mattheos, N. Problem-based learning in academic health education: A systematic review. European Journal of Dental Education. 2010; 14(1): 55-64. PMid:20070800 http://dx.doi.org/10.1111/j.1600-0579.2009.00593.x

[13] Townsend, G. Problem-based learning interventions in a traditional curriculum are an effective learning tool. Evidence-Based Dentistry. 2011; 12(4): 115-116. PMid:22193657 http://dx.doi.org/10.1038/sj.ebd.6400829

[14] Taber, K. Classroom-based research and evidence-based practice: A guide for teachers. 2007; Los Angeles; London: Sage.

[15] Kuiper, RA, Pesut, DJ. Promoting cognitive and metacognitive reflective reasoning skills in nursing practice: Self-regulated learning theory. Journal of Advanced Nursing. 2004; 45(4): 381-391. PMid:14756832

http://dx.doi.org/10.1046/j.1365-2648.2003.02921.x 